\title{
Gay Men's Health and Identity: Social Change and the Life Course
}

\author{
Phillip L. Hammack ${ }^{1} \cdot$ David M. Frost $^{2} \cdot$ Ilan H. Meyer ${ }^{3} \cdot$ David R. Pletta $^{1}$
}

Received: 18 March 2016/Revised: 17 March 2017/ Accepted: 5 April 2017 / Published online: 5 June 2017

(c) Springer Science+Business Media New York 2017

\begin{abstract}
Due to significant historical change in the late 20th and early 21 st century related to both health and cultural attitudes toward homosexuality, gay men of distinct birth cohorts may diverge considerably in their health and identity development. We argue that research on gay men's health has not adequately considered the significance of membership in distinct generation-cohorts, and we present a life course paradigm to address this problem. Focusing on the U.S. as an exemplar that can be adapted to other cultural contexts, we identify five generations of gay men alive today and review unique issues related to health and identity development for each. Implications for research, practice, and advocacy on gay men's health and development are discussed.
\end{abstract}

Keywords Gay men · Homosexuality · Life course ·

History $\cdot$ HIV/AIDS $\cdot \operatorname{PrEP} \cdot$ Sexual orientation

In an early forum on the emergence of pre-exposure prophylaxis (PrEP; see Grant et al., 2010) for HIV prevention held at San Francisco's LGBT Center witnessed by the first author, an argument erupted in the audience between a group of young men in their twenties and a group of men in their fifties. The older men chastised the younger men who admitted that they chose not to use condoms regularly, since they perceived condoms as a barrier to the intimacy they sought in sex. "Every time you do that, you are asking to die," one of the older men said. One of the younger men

Phillip L. Hammack

hammack@ucsc.edu

1 Department of Psychology, University of California, Santa Cruz, 1156 High Street, Santa Cruz, CA 95064, USA

2 Department of Psychology, University of Surrey, Guildford, UK

3 William Institute, School of Law, University of California, Los Angeles, Los Angeles, CA, USA countered, "We can't keep being afraid of sex because you were. We can't carry the burden of everyone who died before us." Men in their thirties and forties (including the first author) were notably silent during the exchange. In all likelihood, they could relate to men of both generations, having developed their sexual lives as gay men with condom use as a strong community norm but having lost few to AIDS.

The heated exchange between these two generations of men at the PrEP forum reveals the way in which social identities and health practices are dynamic and grounded in historical time and place. Sexuality researchers would benefit from a scientific paradigm that recognizes and accommodates the significant social and historical change that has affected gay men's health and identity development over the past half-century. The life course paradigm recognizes identity and health as historically situated, centering the concept of generation in the study of lives in context (e.g., Hammack, 2005; Hammack \& Cohler, 2011). It thus can guide scholars to research questions, practices, and advocacy strategies more clearly aligned with the lived experience of gay men in diverse cultural and historical contexts, with the aim to both understand and enhance gay men's health.

In this article, we illustrate the utility of a life course paradigm in the study of gay men's health and identity development and propose empirical work that embodies this paradigm. We focus on gay men specifically (rather than applying the paradigm across all sexual minorities) because gay men were uniquely impacted by a major health event-the emergence of the AIDS epidemic in the 1980s (Forstein, 2013; Halkitis, 2014). While we expect this paradigm to have relevance to sexual and gender identity minorities across a number of cultural settings, we do not expect uniformity across cultural contexts with regard to specific historical events and their impact on health and identity development. We focus on the cultural context of the U.S. in order to provide an exemplar for adaptation in other national settings in which distinct historical events will be salient. 
We also recognize that within the U.S. significant diversity exists among men who identify as gay owing to the intersections of other identities such as race, class, gender identity, and other social identities (e.g., Bowleg, 2013; Meyer, 2010). The historical events that shape the generational consciousness of a diversity of gay men are not likely experienced in a uniform way because of these intersections, and we note instances of divergence among gay men with intersecting identities throughout the article. Yet we argue that membership in the social category of gay men likely assumes a prominent role in the health and identity development of a diversity of same-sex attracted men owing to major historical events over the past half-century. In other words, although we do not expect uniformity in the way in which diverse gay men experience historical events, we do expect commonality and thus propose salience of certain historical events likely to affect a diversity of gay men.

The ideas we develop in this article may be relevant to bisexual and other same-sex attracted men. Where appropriate, we note ways in which the health and identity development of these men may converge or diverge with men who identify as gay. Similar to young gay men today, younger generations of bisexual men are more likely than members of older cohorts to narrate positive coming out experiences (McCormack, Anderson, \& Adams, 2014). However, bisexual men face identityrelated health concerns distinguishable from those of gay men, including biphobia (e.g., Friedman et al., 2014) and the relative invisibility of a bisexual male community (e.g., Dodge et al., 2012; Kertzner, Meyer, Frost, \& Stirratt, 2009). Nonetheless, we recognize that bisexual men have typically been included in studies of gay men, and hence much of our analysis may be applicable to them as well.

Our notion of health is informed by perspectives in critical health psychology (e.g., Crossley, 2008), the gay men's health movement (e.g., Rofes, 2005), and qualitative studies in which gay men have provided data on the meaning of health for them (e.g., Adams, McCreanor, \& Braun, 2013). In line with these perspectives, we conceive of health not simply as a matter of the absence of disease or engaging in practices that reduce the risk of disease. Rather, health refers to a state of physical and psychological wellbeing (e.g., Adams et al., 2013). Health is thus concerned with more than the absence of pathology in body and mind; it is concerned with the state of individual and social wellbeing (World Health Organization, 1948) in a larger context of stigma and stress for sexual minorities (Meyer, 2003).

\section{Gay Men's Health and the Life Course: Key Principles}

The life course paradigm does not simply guide us to a focus on gay men at different points in their individual development (e.g., adolescence, midlife). Rather, a life course paradigm orients us toward a concern with the intersection of social and historical context and individual development (Cohler \& GalatzerLevy, 2000; Hammack, 2005). A life course, or sociogenic, approach to human development focuses on the social context and stands in contrast to the traditional life span, or ontogenetic, approach, which is only minimally concerned with social context (see Dannefer, 1984). It is noteworthy that the "life course" approach proposed by the Institute of Medicine (Institute of Medicine, 2011) to guide the study of LGBT people is more consistent with an ontogenetic "life span" approach.

The life course approach offers a particularly fruitful paradigm for the study of gay men's health because of the significant social changes that have occurred in the past half-century to create radically divergent contexts of development for different generations of sexual and gender identity minorities (Hammack \& Cohler, 2011). The life course paradigm does not seek to chart "ages and stages" of identity development, as earlier perspectives on sexual minorities did (e.g., Cass, 1979; Troiden, 1979). Rather, scholars who adopt a life course paradigm aim to understand the historical contingencies of human development by emphasizing difference and discontinuity rather than sameness and continuity in the patterning of lives over time (e.g., Cohler, 2007; Hammack, 2005; Hammack \& Cohler, 2011; Plummer, 2010). A life course approach draws our attention away from the idea of human development as either biologically or socially determined (Hammack, 2005), toward a more dynamic view of lives.

The life course paradigm emerged in the 1960s and 1970s, chiefly within the sociology of aging, with the maturation of longitudinal studies in the U.S. that were intended to provide extensive empirical data on human development (see Elder, Johnson, $\&$ Crosnoe, 2003). By following individuals over time, the goal was to map the universal pathways through which they developed and to chart normative trajectories of the life span, anchoring developmental science in a framework of lawful regularities. Yet as scholars began to closely examine the longitudinal data amassed across the twentieth century, the significance of generation-cohort became obvious in patterning the developmental trajectories of individual lives (Phelps, Furtsenberg, \& Colby, 2002). For example, Elder's (1974) pioneering study revealed how social and economic conditions radically altered the life experiences of two generations, depending on when they experienced the disruption of the Great Depression.

A brief sampling of major historical events that have occurred over the past half-century call our attention to how the course of gay men's lives in the U.S. might radically diverge across generations - the Stonewall riots of 1969, the emergence of the AIDS epidemic in the 1980s, the discovery of highly active anti-retroviral therapy (HAART) to manage HIV in 1996, the US Supreme Court's decision in Lawrencev. Texas (2003) decriminalizing gay sex, the marriage equality movement of the 2000s [culminating in the Obergefell v. Hodges (2015) decision that ruled same-sex marriage a constitutional right across all states], and the emergence of PrEP as a highly effective HIV prevention tool. 
Following Elder (1998), we suggest two key principles of a life course paradigm for the study of gay men's health and identity. The first is the principle of historical time and place. According to Elder (1998), "the life course of individuals is embedded in and shaped by the historical times and places they experience over their life-time" (p. 3). Applied to gay men's health and identity development, this principle suggests recognition that a gay man's self-understanding is tied to the historical setting in which he develops. For example, men born in the U.S. in the 1970s and reaching puberty in the 1980s likely developed an awareness of same-sex attraction closely linked to contamination, AIDS, and death as imagined possibilities for the trajectory of their lives. Men born in the 1990s and experiencing puberty in the 2000s developed this same awareness at a time in which the discourse on gay identity in the U.S. focused on marriage equality rather than AIDS. This principle suggests that we understand gay men's identity development within the larger context of how same-sex attraction is spoken about in a social and political context (e.g., Foucault, 1978; Hammack, Mayers, \& Windell, 2013).

A second key principle of the life course paradigm is the principle of timing in lives: "The developmental impact of a succession of life transitions or events is contingent on when they occur in a person's life"(Elder, 1998, p. 3). While the first principle calls our attention to the historical context in which individuals develop, the second principle emphasizes the significance of particular historical events experienced at particular developmental moments in an individual's life. Applied to the lives of gay men, we posit two critical periods of development: (1) puberty, recognized as a "magical age" for sexual awareness (Herdt \& McClintock, 2000) and typically reported in retrospective accounts as the moment at which gay men recognized their same-sex desire and its potential significance for their lives (e.g., Dickson, van Roode, Cameron, \& Paul, 2013); and (2) emerging adulthood (approximately ages 18-29; Arnett, 2004), corresponding to a likely increase in sexual activity and community participation for gay men in the U.S. (e.g., Morgan, 2013).

It is important to note that the life course paradigm allows for a focus on both developmental period and cohort effects, given both are not entirely conceptually or operationally distinct in the reality of lived experience (e.g., Glenn, 1976). Period effects refer to the ways in which a historical event can shape the lives of all individuals alive at the time of its occurrence. Cohort effects most often pertain to differences observed between groups of individuals defined by a shared temporal characteristic or experience (most often birth cohorts). Both have relevance to the development and health of gay men (Martin \& D'Augelli, 2009). The onset of HIV/AIDS in the early 1980 s offers an example. The impact of this event likely manifests in period effects because it increased fear and condom use among the overwhelming majority of gay men alive and sexually active (Martin, Dean, Garcia, \& Hall, 1989). However, the onset of HIV/AIDS may have distinct cohort effects in that those gay men coming of age at this time may have imagined futures colored by the perceived inevitability of death and the pairing of HIV and gay identity. By contrast, older cohorts had already experienced life without HIV and thus its arrival may have differentially impacted their identities. A life course paradigm is inclusive of these complex aspects of development in sociohistorical context and their relevance for the identities and health of gay men (Martin \& D’Augelli, 2009).

\section{Five Generations of Gay Men in the U.S.}

\section{Defining the Generations}

The question of how to define a generation has been a concern of life course theory and the sociology of aging for some time (e.g., Berger, 1960; Kertzer, 1983; Mannheim, 1923/1959; Rosow, 1978; Ryder, 1965). We use the terms generation and cohort interchangeably, since their meaning and use in the social science literature overlaps considerably. The Oxford English Dictionary defines a generation as "all of the people born and living at about the same time, regarded collectively" (Generation, 2016), while it defines a cohort as "a group of persons having a common statistical characteristic, especially that of being born in the same year" (Cohort, 2016).

Although a life course perspective has occasionally appeared in theory and research on LGB lives (e.g., Boxer \& Cohler, 1989; Hammack, 2005; Hammack \& Cohler, 2009; Plummer, 2010), few attempts to establish precise cohorts have occurred. Early social theorists argued for the significance of "crucial cohort experiences" (Rosow, 1978) or "cohort-defining events" (Ryder, 1965)_experiences or events so monumental as to create a shared social consciousness and generational identity. Consistent with these perspectives, previous attempts to define generations of sexual minorities have emphasized the impact of shared historical events on self-understanding and the development of a sense of social identity (e.g., Cohler, 2007; Grierson \& Smith, 2005; Hammack \& Cohler, 2011; Parks, 1999; Robinson, 2008). Events such as Stonewall, the declassification of homosexuality as a mental illness, and AIDS have figured prominently in these studies. Studies that have conducted comparative analyses of cohorts have also revealed distinct experiences and concerns, such as different experiences with disclosure and labeling (e.g., Dunlap, 2014; Grierson \& Smith, 2005; Robinson, 2008; Vaccaro, 2009).

To define the cohorts of gay men in the U.S. alive today, we began by identifying key historical events in gay and lesbian history that might influence identity development and health among gay men. Then we considered when these cohort-defining events were experienced in relation to the two critical periods of development noted above (i.e., puberty and emerging adulthood). Our approach was to combine insights from the limited existing inductive research with a deductive approach based on analysis of historical events, including more recent historical events that were not considered in prior studies (e.g., the emergence of PrEP, legal decisions regarding marriage equality). Our goal was to develop hypotheses about cohort differences that can be tested in future 
research and thus to stimulate more inquiry that foregrounds the concept of generation-cohort as a meaningful social identity for gay men's health and identity development.

In identifying cohort-defining events, we were interested both in discrete happenings and in the broader social context of how gay men have been "spoken about" (Foucault, 1982) in cultural discourse at particular historical moments. We recognize that the discourse about gay men in the U.S. has not always been uniform, nor has access to resources related to health and positive identity development. Same-sex attracted men of color, for example, were doubly stigmatized in the early 2000s with the emergence of a discourse on the "down-low" phenomenon (e.g., Boykin, 2004; Martinez \& Hosek, 2005), and they have been disproportionately impacted by HIV for at least a decade (Clerkin, Newcomb, \& Mustanski, 2011; Grov, Rendina, Ventuneac, \& Parsons, 2016; Newcomb \& Mustanski, 2013), currently constituting a higher rate of new HIV infections relative to other demographic groups (Centers for Disease Control \& Prevention, 2016). As we outline the five generations below, we note the significance of intersecting identities for gay men with regard to both health and identity development.

We identified four historical periods in U.S. gay and lesbian history characterized by distinct events and discourses of relevance to gay men's health and identity. During the sickness era (prior to the late 1960s), same-sex desire was discursively framed as a mental illness, and a larger sexual minority community was largely invisible (Hammack et al., 2013). The liberation era (approximately 1969-1981), punctuated by the Stonewall riots and subsequent visibility for sexual minorities, saw the thriving of gay and lesbian communities in urban centers and a new discourse on homosexuality as indicative of a sexual identity rather than a form of psychopathology (Hammack et al., 2013). The AIDS era (approximately 1981-early 2000s) saw a return to the association of homosexuality with illness and disease, accompanied by setbacks for social equality realized in policies like the 1996 Defense of Marriage Act (DOMA). Finally, the equality era (approximately 2003-present) is characterized by the gradual but now widely held recognition of sexual minority identities and communities as legitimate and worthy of equal treatment and protection under the law (Keleher \& Smith, 2012).

Within these historical eras, we identified four specific cohortdefining events (CDEs)— events that marked likely turning points in the collective consciousness of gay men, with implications for their experience of identity and health (see Table 1). Our selection of these events is based on an analysis of historical and cultural materials such as news documents and literature. We recognize, however, that the significance of some events (e.g., the emergence of PrEP) remains somewhat of an empirical question. We hope that the framework we present here will stimulate research that can examine the extent to which these historical events indeed have personal meaning for gay men. We now outline the five distinct generations of gay men we posit are living in the U.S. today, specify the historical context of their development, and explore their likely divergences in health and identity development. The distinct labels we have selected for each generation reflect the dominant discourse of male homosexuality during critical periods of development: sickness, liberation, AIDS, and equality.

\section{The Sickness Generation}

For most of the twentieth century, same-sex desire was classified as a sickness, representing a diagnosable mental illness in the Diagnostic and Statistical Manual (DSM) of the American Psychiatric Association (see Hammack et al., 2013). There was debate within the scientific community about whether homosexuality ought to be considered a form of psychopathology, and some scientific activists argued for the "normality" of same-sex desire (see Bayer, 1987; Minton, 2001). Yet prior to the national visibility for the gay and lesbian civil rights movement realized by the Stonewall riots of 1969 and the removal of homosexuality from the DSM in 1973, the dominant discourse about homosexuality was that homosexuality in and of itself constituted a disease (Hammack et al., 2013; Herek, 2010).

Gay men who developed during this era likely viewed their sexual desires, practices, and identities through the prism of disease and abnormality, deeply internalizing stigma (see Cohler, 2007; Hammack \& Cohler, 2011; Loughery, 1998). We refer to gay men who came of age during this era as members of the Sickness Generation to recognize the dominant, pathologizing discourse of sexual diversity to which they were exposed at critical points in their development. We recognize that this label may be an uncomfortable one for men of this generation, yet we employ it precisely to capture the extent to which societal discourse and cultural attitudes so strongly equated homosexuality with pathology at the time, likely leading to formidable early psychological challenges.

Gay men of the Sickness Generation were born approximately in the 1930s and experienced childhood, adolescence, and early adulthood with the dominant discourse of homosexuality as illness (see Table 1). Today in their seventies and eighties, these men experienced early adulthood just as the gay and lesbian civil rights movement was beginning to be established in the U.S. (i.e., the 1950s) but was still highly marginalized. Many of these men were not likely active in the movement in their early adulthood and instead concealed their sexual identities and assumed a heterosexual identity, often marrying women and having children with them (Cohler \& Hostetler, 2007; de Vries \& Herdt, 2012; Muraco, LeBlanc, \& Russell, 2008). Many of these men tended to come out later in life (Cohler \& Hostetler, 2007) and experienced middle age during the subsequent eras of gay and lesbian liberation (approximately 19691981) and AIDS (approximately 1981-early 2000s). Men who concealed their same-sex desire into the late 1980s were exposed to media portrayals of behaviorally bisexual men as a source for HIV transmission between gay and straight communities (McCormack et al., 2014; see Miller, 2001). Consequently, a stigmatizing narrative of homosexuality and disease likely impacted more than gay- 


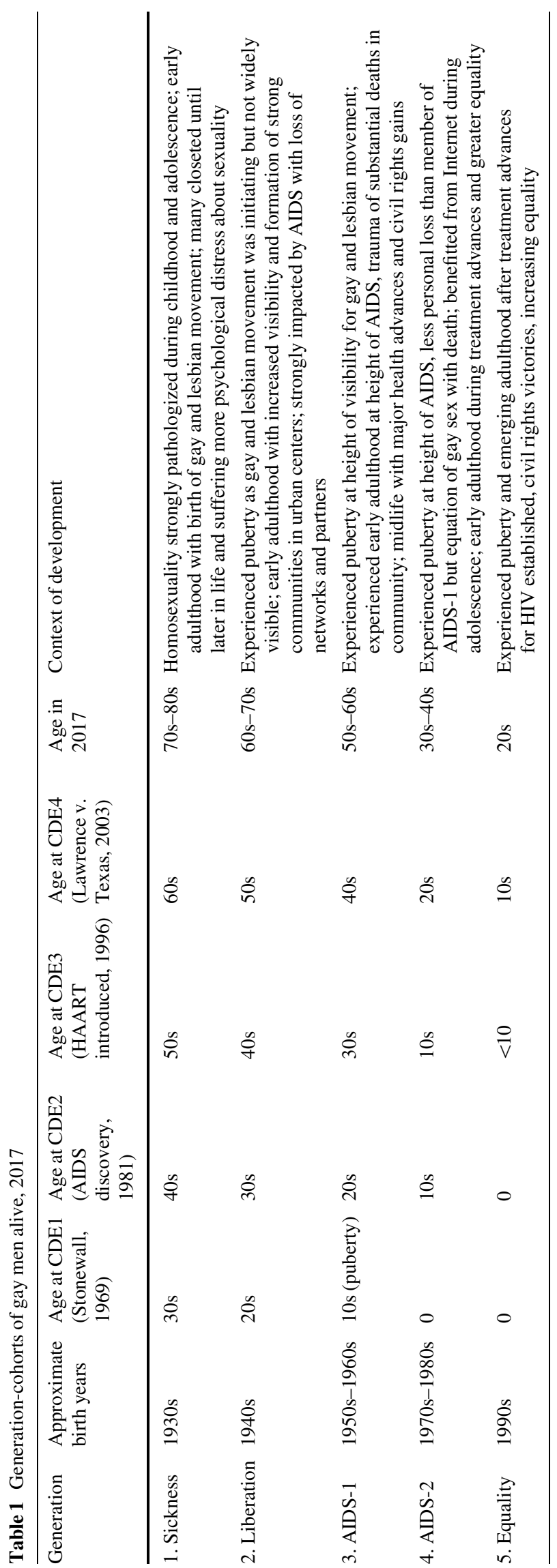

identified men, extending broadly to men with same-sex desire in the U.S. during the AIDS epidemic. Because homosexuality was still classified as a disease during the childhood and early adulthood of these men, many likely had negative experiences with medical and mental health professionals when they sought help (e.g., Duberman, 1991; see Cohler, 2007; Hammack \& Cohler, 2011).

Men of color who are members of this generation navigated not just deeply stigmatizing discourse about homosexuality but also an era of explicit racism and violence against racial and ethnic minorities. They encountered racism within early sexual minority communities and the homophile movement (e.g., Stein, 2012), as well as homophobia and heterosexism within racial and ethnic minority communities and the larger Civil Rights Movement (e.g., Icard, 1985; Loiacano, 1989). Unfortunately, empirical research with gay and other same-sex attracted men of this generation has been conducted exclusively with white men, and the recent focus on men of color has tended to study younger generations of men. Hence we can only speculate on how intersecting identities might have influenced the health and identity development of these men. Research that focuses specifically on the experiences of men of color of this generation is essential to understand the impact of "double stigma" they likely experienced at critical periods in their development.

Men of the Sickness Generation alive today would have experienced several eras of gay and lesbian history, living long enough to witness the major social and political gains of the most recent equality era (2003-present). Yet their initial experience of same-sex desire as a source of significant stigma and shame well into their adulthood may have shaped their sexual subjectivities in ways that exacerbated their experience of minority stress (Cohler \& Galatzer-Levy, 2000; Cohler \& Hostetler, 2007; de Vries, 2013). Men of color may be further affected, given the impact of stress from both sexual and racial minority status (Meyer, 2010). On the other hand, members of this generation who have been able to successfully negotiate massive social changes and community traumas may demonstrate considerable "crisis competence" (Cohler \& Hostetler, 2007; see also Berger \& Kelly, 2001). Those who gained mastery over the possibility of stigma and have traversed these challenging personal and social contexts demonstrate significant psychological resilience. In other words, though struggle may characterize the social ecology of development for members of the Sickness Generation, many have demonstrated the ability to transcend the possibility of life-story contamination and instead construct redemptive narratives (e.g., Cohler, 2007; Hammack \& Cohler, 2011).

The identity development process of men of the Sickness Generation is likely distinct from men of subsequent generations in the extent to which they experienced a social context of development particularly hostile to same-sex desire (de Vries, 2013; Fenkl, 2012; Fredriksen-Goldsen \& Muraco, 2010). As Peacock (2000) suggests in his study of gay male aging, gay men develop their identities at different times depending upon their 
process of self-acceptance and disclosure of sexual orientation. For men who experienced much of their development during the particularly hostile context of the sickness era, we would expect considerable variability in identity development, such that milestones such as the age of coming out might be somewhat inconsistent (though Calzo, Antonucci, Mays, and Cochran [2011] discovered that a majority of sexual minorities retrospectively recall coming out between ages 12 and 20 across birth cohorts). In addition, the labels that men of this generation use to self-identify might vary, with terms such as homosexual more popular than gay during their adolescence and early adulthood and hence more likely to be used for self-identification (e.g., Adelman, Gurevitch, de Vries, \& Blando, 2006). The more recent term queer used by some men of younger generations may be particularly unpopular for men of the Sickness Generation because of its more widespread derogatory use during their early development (de Vries, 2013).

The health of men of the Sickness Generation should be considered in light of their early and longstanding negotiation of stigma and social exclusion for most of their lives, as well as the impact of HIV/AIDS (de Vries, 2013). Men of this generation were approximately in their forties when AIDS was first identified in gay men in 1981, and like subsequent generations they lost many loved ones to the epidemic. Those alive today survived this period of collective trauma and likely experience the psychological legacy of these many losses. Yet because of the variability in this cohort with regard to identity development and community engagement compared to the subsequent two generations, we might find more variability in these men's experiences with the AIDS epidemic, with men who came out later in life having not experienced the same mass losses as men who came out at younger ages. Further, the pairing of gay identity with sickness and pathology in men of this generation was likely detrimental to their social wellbeing and may have impacted their ability to form and maintain healthy relationships. Men's geographic location also certainly created diversity of experience during this era, as men in large gay communities such as New York and San Francisco experienced greater loss but also more community support in the context of widespread cultural stigma (e.g., Armstrong, 2002; Martin, 1987; Richards, Wrubel, \& Folkman, 1999).

What likely unites men of the Sickness Generation most is the legacy of developing during an era in which same-sex desire was framed as a disease, thus internalizing stigma, concealing their sexual identities, and experiencing other significant minority stressors (de Vries, 2013). In addition, the experience of health care and other service institutions as hostile to the unique concerns of gay men may remain a legacy for men of this generation, as they continue to report lack of access to supportive care (Fredriksen-Goldsen \& Muraco, 2010) or fears of discrimination in health contexts (Jackson, Johnson, \& Roberts, 2008). As a result, some researchers and practitioners have noted that many men of this cohort are invisible, likely to be "silent" about their unique health and social support needs (e.g., Butler, 2004), and less likely to disclose their sexual identities to health practitioners than younger men (e.g., Clover, 2006).

\section{The Liberation Generation}

As indicated in Table 1, the Stonewall riots of 1969 represent a symbolic significant cohort-defining event for gay men alive today and punctuated a shift in discourse on sexual diversity as a source of liberation. Major events were occurring throughout the 1950s and 1960s that led to the establishment of the modern gay and lesbian civil rights movement (see Faderman, 2015; Hirshman, 2012), but the Stonewall riots brought national visibility to the movement in a way previously unrealized (Carter, 2004; Duberman, 1993). Stonewall exposed gay and other same-sex attracted men throughout the U.S. to the size and significance of the larger sexual minority community, although this exposure was likely more pronounced for men who resided in or near major urban centers.

Though sizeable gay and lesbian communities had already formed in major US cities after World War II (D'Emilio, 1983; Sadownick, 1996), they existed in more clandestine forms until the 1970s. Visibility of these communities increased dramatically during this liberation era (Hirshman, 2012), and the erosion of the sickness narrative of homosexuality gave way to demonstrations of pride and community rituals such as the emergence of Gay Pride (originally called Christopher Street Liberation Day) as an annual celebration of the Stonewall riots (Duberman, 1993). Open expression of same-sex desire became possible in some communities, especially in big cities with "gay ghettos" (Levine, 1979), along with a social and political culture within a more unified gay community that encouraged challenge of the status quo (Armstrong, 2002).

Gay men who came of age in the U.S. during thisera(1969-1981) had opportunities, unparalleled before, to immerse themselves into gay and lesbian communities in urban settings, likely increasing possibilities for enhanced psychological and social wellbeing compared to prior generations. These men likely experienced a dramatic shift in the meaning of same-sex desire, from a source of shame to a source of pride (Cohler, 2007). They also likely experienced more sex and sexual pleasure, with new institutions in urban communities openly allowing for connection (Sadownick, 1996). We refer to men who came of age during this era as members of the Liberation Generation.

Gay men of the Liberation Generation experienced childhood and adolescence just as the nascent gay and lesbian civil rights movement was emerging in the 1950s (see Table 1). In their early adulthood, many were able to participate in the movement and to benefit from a coherent and strong community in major urban centers (D'Emilio, 1983; Sadownick, 1996). Though these men initially likely experienced their same-sex desires through the lens of the sickness discourse, those who actively participated in the gay and lesbian movement were able to redefine the meaning of a 
sexual minority identity (Hammack \& Cohler, 2011). Today in their sixties and seventies, these men experienced the transition from the sickness to the liberation era during their emerging adulthood. Their identity development may diverge, then, from members of the Sickness Generation in that they may be more likely to have come out at a younger age, become active participants in the gay community, and begun to have sex and relationships outside the clandestine contexts of the sickness era (e.g., Boxer, 1997; Kertzner, 2001; Schope, 2002). Men of this generation might be less likely than men of prior generations to have concealed their same-sex desire or engaged in heterosexual unions or marriage prior to coming out (e.g., Cruz, 2003).

Men of the Liberation Generation experienced the major gains of the liberation era, but they experienced the cohort-defining event of AIDS in 1981 when they were at the peak of their adulthood, approximately in their thirties. As a consequence, they may have been more impacted by AIDS than men of the Sickness Generation, both because they were younger and more sexually active when AIDS struck and because they likely experienced less internalized stigma and hence participated in a more sex-positive community before AIDS emerged (i.e., the 1970s). In his study of men of this generation, Cruz (2003) found that almost $70 \%$ of respondents reported that they were impacted by HIV/AIDS. The experience of AIDS bereavements also figured prominently in Kertzner's (2001) analysis of life narratives of men of this generation, and Martin and Dean's (1993) longitudinal study showed a marked increase in AIDS-related bereavement and psychological distress among men of this generation over a 7-year period.

Men of the Liberation Generation entered midlife as health advances to treat HIV were emerging but with remaining uncertainty about the future of a complete life course (Kertzner, 1997). Survivors of this generation experienced the emergence of HAART while in their forties and the shift in discourse from AIDS to political equality while in their fifties. Like members of the Sickness Generation, men of the Liberation Generation experienced several eras in the history of sexual minorities (i.e., sickness, liberation, AIDS, and equality). But because they experienced the gains of the liberation era at a critical period of development (i.e., early adulthood), their identity development process likely diverges from the previous generation. For example, men of the Liberation Generation may report less stigma about being gay than men of the Sickness Generation (e.g., Cruz, 2003). Like men of the subsequent generation, though, their experience of the cohort-defining event of AIDS at the peak of their adulthood likely introduces major challenges for their health and identity development.

The experience of gay men of this generation was far from uniform, however, and likely diverged according to factors such as race and ethnicity. Like men of color who are members of the Sickness Generation, men of color in the Liberation Generation had to navigate racism within the sexual minority community and the gay and lesbian movement, as well as heterosexism and homophobia in racial and ethnic minority communities and the Civil Rights Movement. Despite the participation of people of color in the Stonewall riots, Black and other gay men of color were not integrated into primarily white gay communities. For example, in several cities, including New York City's Harlem neighborhood, Black gay men had a thriving community since at least the 1930s, but it was mostly separated from the emerging gay white community. During the liberation era, Black gay men of both the Sickness and the Liberation generations, who had just recently gone through the Civil Rights era, experienced conflict and even competition between allegiances to a Black versus gay identity - as Conerly (2001) described it, "Are you Black first or are you queer?" Being "Black gay" or "gay Black" referred to the necessity of making one identity and one struggle primary (Wilson \& Miller, 2002). For some, being "gay-identified Black" was associated with assimilation and abandonment of one's Black roots (Johnson, 1982; Meyer \& Ouellette, 2009).

Although men of this generation generally experienced more opportunities to build and connect within communities of other sexual and gender minority individuals, there was likely variability in men's experience of these communities, with many men of color encountering racism within them (Haile, Rowell-Cunsolo, Parker, Padilla, \& Hansen, 2014). This variability is important to consider from a public health point of view, given community connectedness can act as a group-level coping mechanism and "buffer" against the negative effects of stigma and discrimination on mental health and sexual risk (Frost \& Meyer, 2012; Meyer, 2003; Ramirez-Valles, Kuhns, Campbell, \& Diaz, 2010). In one of the only studies of men of color of this generation, Woody (2014) found that African American men reported feelings of alienation from the African American community, having to conceal their same-sex desires, but also an aversion to labels of the largely white LGB community.

\section{The AIDS-1 Generation}

The social and political successes of the liberation era were crushed by the emergence of the AIDS epidemic in 1981, which by the end of the 1980s had killed nearly 75,000 gay men (Centers for Disease Control and Prevention, 2005). Gay men experienced the AIDS epidemic as a significant collective trauma, with countless seemingly healthy young men dying quickly on a regular basis (Martin, 1988; Morin, Charles, \& Malyon, 1984). The identification of the first cases of AIDS in 1981 represents another cohort-defining event for men alive at the time, likely influencing their experience of health and identity development. The AIDS era was characterized not just by the devastation of the disease itself but also the accompanying discourse of the antigay "religious right" and "moral majority" that went so far as to claim that AIDS was punishment for the "immorality" of gay sex, creating a major context of stigma for all same-sex attracted men and for people with AIDS (Herek \& Glunt, 1988) and leading to gay men's practices and bodies becoming subjects of contamination during this era. 
Despite this collective trauma, the gay and lesbian community showed tremendous growth during the AIDS era. Community-based activism formed in the liberation era facilitated a strong response that challenged AIDS stigma discourse and advocated for treatment and research advances (e.g., Katoff \& Dunne, 1988; Wachter, 1992). As a result of both community activism and governmental and non-governmental organizations' resources aimed to combat AIDS, LGBT-based organizations grew greater roots in the community than before and established community-based institutions (Bernstein, 2002). The need to confront AIDS, together with the growth in paid and volunteer positions in the community, led to greater involvement and collaborations between gay men and lesbians than was seen in prior eras (Bernstein, 2002). AIDS also exposed many deficiencies in the legal and policy arena-for example, it exposed blatant discrimination in how gay couples were seen by courts around inheritance - and made the issue of lesbian and gay rights more compelling and urgent (Bernstein, 2002). The identities and sexual practices of gay men developing in the AIDS era departed dramatically from the sense of pride and sexual freedom experienced during the liberation era, with gay men now associating sex with potential death and adjusting their practices accordingly (e.g., Juran, 1989; Martin et al., 1989).

Because this era was punctuated by two cohort-defining events-the emergence of AIDS in 1981 and the introduction of effective combination therapies (i.e., HAART) in 1996we posit that two distinct AIDS generations exist. Members of the AIDS-1 Generation experienced more personal losses to AIDS, since they were older and more sexually active than members of the AIDS-2 Generation at the height of the epidemic. Members of the AIDS-2 Generation grew up with AIDS as intrinsically linked to gay identity and gay sex, but also when effective prevention (e.g., condom use) and later treatments (e.g., HAART) made it less likely for them to experience direct personal losses to the epidemic.

We thus distinguish two generations of gay men who experienced the AIDS era in distinct ways. Men of the AIDS-1 Generation were born in the 1950s and 1960s and were children around the peak of the gay rights movement, symbolized by the Stonewall riots. They experienced the shift from the sickness to the liberation era around puberty, whereas men of the Liberation Generation had experienced this shift in early adulthood (twenties) and men of the Sickness Generation in middle adulthood (thirties and forties). Members of the AIDS-1 Generation experienced the liberation era in early adulthood and likely benefitted from the thriving open gay culture and community of urban centers in the 1970s (Levine, 1979). Yet because these men were at a period of perhaps the highest sexual activity of any generation at the time, their generation was devastated by AIDS (Halkitis, 2014). They experienced the transition from the liberation era to the AIDS era at the height of adulthood. Today these men are in their fifties and early sixties and perhaps the most affected by AIDS, still negotiating the cultural trauma only recently beginning to be fully processed (Halkitis, 2014).

Gay men of the AIDS-1 Generation experienced a radical break between the culture of the 1970s, characterized by a sense of evolving freedom to express one's same-sex desire and form communities (D'Emilio, 1983), and the sudden plague that emerged with AIDS. AIDS represents a turning point in the larger cultural narrative of gay male sexuality in that it came to fulfill images of contamination and sickness that were central to the original sickness narrative of homosexuality (Hammack et al., 2013). In other words, the sudden association of gay male sexuality with the rapid physical deterioration of otherwise healthy young men resuscitated the waning sickness narrative of homosexuality and thus presented a new context for internalizing stigma and shame around one's sexual desires. AIDS-related stigma became pervasive, with extraordinary public anxiety about the disease, in part because of its association with homosexuality (Herek \& Glunt, 1988).

In the 1980s, the state of gay men's health became a "public health and psychological emergency" (Batchelor, 1984), and gay men became targets of prejudice and widespread cultural fear for their contamination (Batchelor, 1988; Herek \& Glunt, 1988). The language of "health crisis" assumed prominence in the community, with the emergence of the "Gay Men's Health Crisis" (GMHC) model (Katoff \& Dunne, 1988; Kayal, 1993). Gay male sexual practices shifted dramatically during the AIDS era (e.g., Juran, 1989; Martin, 1986, 1987; Martin et al., 1989; McKusick, Horstman, \& Coates, 1985; Winkelstein et al., 1987). Men reported fewer sexual partners and substantially more condom use over time, especially once transmission of HIV became better understood. In a content analysis of the language of gay male personal ads from 1978 to 1988, Davidson (1991) found a substantial increase in health-related language and language related to sexual exclusivity. AIDS thus presented a radical break with prior cultural norms around sex and relationships among gay men.

Beyond shifts in larger cultural and behavioral norms, men of the AIDS-1 Generation experienced significant social and psychological trauma during their early adulthood. Studies conducted during the AIDS era suggest that men of this generation experienced greater psychological distress due to AIDS than men of the prior (i.e., Liberation) generation (e.g., Joseph et al., 1990). Odets (1995) described the unique psychological challenges of HIV-negative men during the AIDS era, including the experience of survivor's guilt and the challenges of navigating relationships with serodiscordant partners.

As for prior generations, intersecting identities likely assumed prominence in the health and identity development of same-sex attracted men. Loiacano's (1989) study with African American men of this generation revealed challenges with integrating racial and sexual identities, given the experience of exclusion from both racial and sexual minority communities. Chan's (1989) study with Asian American men of this generation suggested that they were more likely to identify with the sexual minority community 
than the Asian American community, but they reported more discrimination based on their sexual minority identity than their ethnic minority status. Martinez and Sullivan's (1998) study of African American gay men and lesbians of this generation challenged prior stage-based models of gay identity development, revealing the extent to which those models were rooted in the experiences of white gay men and lesbians. The more recent study of Haile, Padilla, and Parker (2011) revealed the way in which HIV-positive African American men of this generation navigated multiple sources of stigma (based on race, sexual identity, and HIV status) during the aging process. These studies reveal the extent to which men of color of the AIDS-1 Generation experienced compounded stigma and have historically struggled to reconcile conflicts rooted in their intersecting identities. Though other generations of men of color might have shared this experience, this cohort was the first for which these experiences were clearly documented.

\section{The AIDS-2 Generation}

We distinguish between gay men who were in early adulthood at the cohort-defining event of AIDS in 1981 (members of the AIDS1 Generation) and men who were in childhood or early adolescence at the time and thus less likely to have been sexually active and socially embedded within the gay community. Members of what we call the AIDS-2 Generation were born in the 1970s and 1980s, just prior to or during the height of the epidemic, and thus became aware of their same-sex desire at a time when gay identity was synonymous with disease and death. HIV/AIDS thus figured prominently in these men's sexual subjectivities (Herdt \& Boxer, 1993), but they were less likely to be directly impacted by losses.

Men of the AIDS-2 Generation likely benefitted from knowledge about effective HIV prevention as well as the emergence of highly effective treatments (i.e., protease inhibitors) as they entered young adulthood. Compared to members of the AIDS-1 Generation, these men may have been less likely to lose partners and social networks to the disease. In addition, men of this generation experienced adolescence and emerging adulthood at a time in which the cultural discourse shifted away from pathologizing and demonizing homosexuality toward embracing gay identity as a legitimate and immutable trait (e.g., LeVay, 1996). By the 1990s, health and mental health professionals had established a consensus that encouraged gay men to accept, rather than to attempt to change, their identities (Hammacket al., 2013). Hence, members of this generation benefitted from a new cultural narrative of homosexuality as a legitimate expression of human diversity.

Members of the AIDS-2 Generation were studied in the 1990s as research on "gay adolescence" expanded dramatically (e.g., Herdt \& Boxer, 1993; Remafedi, 1994; Rotheram-Borus, Hunter, \& Rosario, 1994; for critical reviews, see Savin-Williams, 2001, 2005). These studies revealed the way in which sexual health behavior became paramount to young men of this generation (e.g., Remafedi, 1994), as well as the significant social and psychological challenges they experienced as they developed in a heterosexist and homophobic society (e.g., Flowers \& Buston, 2001; Herdt \& Boxer, 1993). In their ethnographic study of this cohort in Chicago, Herdt and Boxer (1993) documented the significance of immersion into the gay community and participation in its rituals as key for youth of this generation.

Members of this generation witnessed the emergence of the Internet in the 1990s as a new social context facilitating interaction among gay men in ways previously impossible (e.g., Weinrich, 1997). Since its emergence, the Internet has become a significant context for gay men's sexual and social experience (Grov, Breslow, Newcomb, Rosengerberger, \& Bauermeister, 2014; Harper, Bruce, Serrano, \& Jamil, 2009; Mustanski, Lyons, \& Garcia, 2011), and its availability for men of the AIDS-2 Generation at a critical developmental moment (i.e., adolescence) distinguishes the course of these men's lives from previous generations. However, variability in access and use by race/ethnicity, socioeconomic status, and rural location within this generation likely mirrored that in the general population. Thus, the availability of this important resource for social development and health education (e.g., finding information about HIV risk) may not have impacted men of this generation equally.

Men of color of the AIDS-2 Generation are far better represented in empirical research compared to prior generations. The consistent theme of challenge with regard to integrating racial and sexual identities emerges from studies of men of color of this generation (e.g., Bowleg, 2013; Christian, 2005; Goode-Cross \& Tager, 2011; Hunter, 2010), as does the theme of experiencing ethnic minority stress in the gay community but sexual minority stress in the ethnic minority community (e.g., Hidalgo, Cotten, Johnson, Kuhns, \& Garafalo, 2013). The phenomenon of ethnic minority men (typically African American and Latino) rejecting gay identity labels and identification with the gay community but engaging in same-sex practices is particularly well documented for men of this generation (e.g., Dodge, Jeffries, \& Sandfort, 2008; Martinez \& Hosek, 2005). This phenomenon has important implications for health and speaks to the need for health-related interventions such as HIV prevention to target men beyond the gay community (e.g., Mays, Cochran, \& Zamudio, 2004; Voisin, Bird, Shiu, \& Krieger, 2013). It is important to note, however, that studies that include men of color of this generation also reveal positive health and mental health outcomes, such as resilience and selfefficacy (Wilson et al., 2016), as well as positive narrative accounts of integrating their racial and sexual identities (Meyer \& Ouellette, 2009). Thus, there is evidence of diversity among samesex attracted men of color in their health and identity development, and intersecting identities create variable developmental trajectories for all same-sex attracted men of color.

\section{The Equality Generation}

With the emergence of highly effective treatments and prevention strategies for HIV/AIDS came a gradual shift in the discourse about gay men from contaminated to worthy of equal 
treatment under the law, and the AIDS epidemic may have come to humanize gay men in ways previously unrealized. Sexual identity emerged as an indicator of diversity, along with gender, race, ethnicity, and the like. Beginning in the late 1990s and steadily increasing to today, stigma and discrimination based upon sexual minority status are increasingly seen as violating principles of equality and liberty central to American values (Keleher \& Smith, 2012).

The key cohort-defining event of this era likely occurred with two court decisions in 2003: Lawrence v. Texas, the US Supreme Court decision that ruled all state sodomy laws unconstitutional; and Goodridge v. Department of Public Health, the Massachusetts Supreme Court decision that legalized same-sex marriage in the commonwealth (representing the first in the U.S.). During this era, both popular and scientific discourse about gay men (and other sexual minorities) shifted from a focus on AIDS to issues of legal rights, especially the right to marry (e.g., Badget, 2011; Fingerhut, Riggle, \& Rostosky, 2011; Maisel \& Fingerhut, 2011; Rostosky, Riggle, Horne, \& Miller, 2009), culminating in the 2015 Obergefell v. Hodges US Supreme Court decision that legalized same-sex marriage across the nation. Gay men developing in this era were probably more likely than men of any previous generation to think of their identities as a normative form of diversity in a social context increasingly accepting of non-heterosexual identities and relationships. In addition, with the emergence of new highly effective HIV prevention options such as PrEP, views about sex, sexual practices, and sexual health have likely come to more closely resemble men who came of age in the liberation era, with gay sex less likely to be viewed as inherently contaminating.

Men of the Equality Generation may also be more likely to hold multiple, concurrent sexual identities or prefer not to identify with a sexual identity label. Some sexually fluid men have been found to identify as gay, straight, or bisexual depending on social context and their partner's gender, while others believe these labels inadequately express their sexuality (Baldwin et al., 2015). Additionally, these men may be more likely to fluctuate their sexual identities to account for temporal changes in their attraction to men and women (Katz-Wise \& Hyde, 2015; SavinWilliams, Joyner, \& Rieger, 2012). As attitudes toward gender and sexual identity diversity continue to shift in the U.S., further research is needed to explore the relationship among generationcohort, sexual identification, and health outcomes for men with same-sex desire.

With regard to health, men of the Equality Generation continue to experience disproportionate levels of HIV and sexually transmitted infections (STIs) compared with heterosexual youth (e.g., Newcomb \& Mustanski, 2014). The P18 Cohort Study initiated by Halkitis and colleagues has sought to examine factors associated with sexual health and risk for men of this generation, finding high levels of drug use and mental health burden among men over time (e.g., Halkitis et al., 2014, 2015). The experience or expectation of stigma may play a role in young men's health behavior, with one study finding an association among stigma, rejection sensitivity, and alcohol and tobacco consumption (Pachankis, Hatzenbuehler, \& Starks, 2014).

With regard to life-course development, men of this generation may be more likely to view their trajectories and possibilities for intimacy along more similar lines to their heterosexual peers than men of previous generations (Marzullo \& Herdt, 2011). With marriage a legal possibility and a part of the life-course imaginary for many of these men during their adolescence, they may be more likely to see their futures along a more heteronormative trajectory than men of prior generations, including rites of passage such as marriage and even the construction of a conventional family with children (e.g., D'Augelli, Rendina, Sinclair, \& Grossman, 2006; Frost, Meyer, \& Hammack, 2015). As Bauermeister (2014) discovered, men of this cohort with fatherhood aspirations living in states with marriage bans were more likely to experience psychological distress and low self-esteem, revealing the way in which social policies impact psychological experience. It is noteworthy that men of this generation even have such aspirations, given the historical challenges of becoming fathers outside the context of a heterosexual union.

Men of color of the Equality Generation are disproportionately impacted by HIV, with higher rates of new infection than white men (Clerkin et al., 2011). Studies have suggested notable misconceptions about HIV prevention tools, such as PrEP or post-exposure prophylaxis (PEP), among men of color of this generation (Mutchler et al., 2015), suggesting that current prevention messaging strategies may favor white gay men. Studies also suggest continued struggles for men of color to disclose their sexual desires and identities within communities of color (e.g., Patton, 2011), revealing likely challenges in self-labeling, identity development, and community connectedness. Threats to hegemonic masculinity may create unique challenges among men of color who experience same-sex desire (Gonzalez, 2007). Among men of color of this generation, Reed and Miller (2016) found elevated reports of oppression and social isolation for those most vulnerable to contracting HIV. The formidable social and psychological challenges experienced by young men of color appears to thwart effective HIV prevention messaging, as many of these men develop apathetic views toward their own health and wellbeing (Voisin et al., 2013).

\section{Conclusions and Implications for Research, Practice, and Advocacy}

Before offering conclusions and suggestions for future research, we note some limitations to the scope of the proposed life course paradigm for understanding the influence of generation-cohort on gay men's health and identity development. We have noted the significance of historical time and place in shaping generation-cohort defining experiences. However, our argument has been primarily focused on the U.S. cultural context. Even in the U.S., the majority of research on gay men has not taken into account the unique experiences of bisexual men and of men of 
color or men living far from urban centers, so the present framework must be open to adaptation.

Gay men in other nations and non-white U.S. gay men may not have experienced the same events within the same timing and social context as the men in the generations proposed here. In fact, homosexuality itself remains illegal in many countries, and HIV/AIDS prevention technologies are less accessible in rural parts of the U.S. and less industrialized regions of the globe. Thus, important work needs to be done to conceptualize cohort-defining events and cultural shifts that are relevant to gay men's health and identity development in other countries and regions of the U.S.

Additionally, most of the theory and research reviewed here focused on particular health issues that appear centrally linked to the historical context for gay men over the past half-century -notably, sexual health, mental health, relationship health, health care access and utilization, and social wellbeing. Other key health issues disproportionately affect gay men (e.g., cancer, heart disease; Institute of Medicine, 2011) and warrant further study to isolate age, period, and cohort effects. Future research would benefit from including a variety of health outcomes in order to identify the way in which variability in minority stress experiences across cohorts may be associated with a broad range of health issues.

Our focus was on defining generation-cohorts of gay men given their shared identity and participation in a common community. Research is needed to apply a life course perspective to understand social and historical influences on health and identity development among not only gay men but also other sexual minority groups who have related but distinct sexual identities. Such groups include bisexual and other men who have sex with men, sexual minorities whose lives may have been less defined by HIV/AIDS (e.g., lesbian and bisexual women), transgender people, and newly emerging identity groups such as queeridentified individuals. Because gay and other men who have sex with men have experienced a unique health calamity (i.e., the AIDS epidemic) in recent history (Halkitis, 2014), we believe a life course framework focused distinctly on this segment of the sexual minority community is warranted.

The life course approach is best described as a paradigm for theory development and empirical inquiry on human development (Elder, 1998; Hammack, 2005). The core principles of this paradigm center on the significance of historical time and place and timing in lives, so the paradigm calls attention to the significance of social context and its intersection with distinct life course moments (e.g., puberty, early adulthood) to influence developmental trajectories. We expect the paradigm to have universal relevance in its core principles, but, obviously, there can be no uniformity in its application across cultural settings (Shweder \& Sullivan, 1993), since cohort-defining events always occur in a particular cultural context and may be broadly related to social and political issues that are not necessarily focused on sexual minorities (e.g., the end of Apartheid in South
Africa might be a cohort-defining event for gay men there, since it ushered in a new cultural attitude toward diversity in general). We hope that researchers who study sexual and gender identity diversity in other cultural settings will adapt a life course paradigm for use in those settings.

For sexuality researchers, a life course paradigm challenges the notion that gay men constitute a "species" whose practices and norms can be charted with lawful regularity by calling attention to variability (see Hammack et al., 2013; Savin-Williams, 2005). Like all identities and all cultures, gay identity and the practices of gay men shift with time and place, and the changing social and historical context in which gay men have developed in the past half-century makes generational identity likely more significant than recognized in most research designs. Rather than treating gay men as a unified social category, a life course paradigm seeks to interrogate the historical variability that characterizes gay men's evolving subjectivities and practices in matters of health and identity development.

We offer several specific suggestions for future research anchored in a life course paradigm. First, we have posited specific cohorts of gay men based on a deductive analysis of historical and existing social science literature. We recommend that this outline and the numerous hypotheses we have elaborated with regard to identity and health be examined through empirical study of gay men. We suggest that any research questions regarding health (e.g., questions about sexual health, mental health, and physical health concerns or health behaviors) or identity development (e.g., labeling, disclosure and concealment, community affiliation) consider the possible role of generation-cohort and integrate it into their research designs, especially with regard to sampling and data analysis/interpretation. Second, and related, we suggest the common practice of considering membership in a generationcohort as an independent variable in research. However, this may not be advisable when it is not possible to clearly distinguish the cohort-defining aspects of an event from its effect on all gay men (i.e., period effects). Generational identity ought to be added to the list of other identities and statuses we assume to explain attitudes and behavior, akin to social identities such as race, sex, and class. Generational identity represents another social identity likely to influence the social and psychological experience of individuals. Researchers would do well to consider age not just as a marker for ontogenetic development but rather as an identity associated with sociogenic development (Dannefer, 1984). These shifts in research practices will produce vital knowledge that better recognizes the diversity of gay men's experiences and avoid presenting gay men as a homogeneous group. The knowledge produced will likely aid prevention and intervention efforts related to gay men's health and identity development by identifying distinctions across age groups and other social identities such as race and ethnicity.

While we recognize that some research questions may be more appropriately addressed solely with quantitative methods (e.g., questions of relative frequency and prediction of behaviors, attitudes, or experiences), our third recommendation is that researchers 
make greater use of qualitative methods in studies of gay men's health and identity development. If identity and health are socially and historically situated, researchers must consider the social context and the individual's engagement with that context. Qualitative methods address questions of lived experience and recognize that identities are not destinies and people are actively constructing meaning in a social and political world (Hammack, 2011). In other words, gay male culture and identity is a subject for "thick description" and interpretation (Geertz, 1973), not just epidemiological surveillance. Researchers likely become better advocates for gay men's individual and collective wellbeing when they understand the intentional worlds gay men have constructed to navigate stigma, subordination, and contamination (Frost \& Ouellette, 2011). We echo the calls of others (e.g., Dowsett, 2007) and recognize the growing body of qualitative and mixed-methods research on gay men's health (e.g., Davis et al., 2014; Grov et al., 2008; Wilson et al., 2016), and we further recommend the integration of a life course paradigm to these studies in order to fully examine diverse experiences and developmental trajectories among gay men.

Finally, research would benefit from employing complex longitudinal designs in order to isolate cohort, period, and age effects. Cohort-sequential designs make such precision possible in that they involve the collection and analysis of longitudinal data sequences from two or more cohorts simultaneously (e.g., Anderson, 1993; Costa \& McCrae, 1982; Schaie, 1965). For example, a study using targeted enrollment to recruit men within two or more generation-cohorts and including multiple follow-up assessments with participants over extended periods of time will allow for the examination of (1) cohort effects in the form of unique differences between each generation-cohort at common ages (e.g., a comparison of sexual identity centrality for men in the AIDS-2 cohort at age 35 compared to men in the Liberation cohort at age 35); (2) age effects in the form of change attributable to increasing age at all relevant points in the age range; and (3) period effects by examining similarities (vs. differences) in the impact of a commonly experienced event on all cohorts enrolled in the study (e.g., the impact of marriage equality on men of each of distinct generations).

For clinical practitioners, the life course paradigm suggests that they approach their work with gay men with historical sensitivity and that they are reflexive about their own generational position vis-à-vis gay clients. The life course paradigm suggests that practitioners be mindful of the health-related attitudes and practices of clients in the context of their generational positioning. Men of one generation may be more likely to experience health and mental health concerns as a consequence of their own life histories. Reflexivity is about constantly considering one's own positioning in an encounter, such as may occur in a research or clinical setting (see Shaw, 2010). Practitioners would do well to critically consider how their own views about health, determined at least in part in the course of their own development in a generation-cohort, impact their practice with gay men (Herdt \& Boxer, 1993). For example, practitioners who are members of older generations of gay men watched countless patients die during the AIDS epidemic, and hence they may be more reluctant to shift their preventive message away from anything other than condom use, with everyone, every time. This approach may be at odds with the sexual subjectivities of younger cohorts of gay men, who not only did not experience the AIDS epidemic but also do not view HIV as a lethal illness.

For advocates for gay men and their health, the life course paradigmillustrates how health is not just a matter of individual functioning and adaptation; it is closely linked to the political and historical context of shared membership in a generationcohort. Because it contextualizes gay men's lives in a particular historical location, the life course perspective challenges our scientific paradigm of gay men's health as linked primarily to individual practices or adaptations. Rather, the life course paradigm draws our attention to the link between history and individual development, and hence between culture, politics and health. Our hope is that the emergence of life course theory from margin to center in the study of gay men's health and gay men's lives more generally will highlight the notion that health and wellbeing are not simply personal concerns linked primarily to individual practices. The life course paradigm encourages us to see human development as a deeply social and cultural process - the nature of which is always on the move, and so there is always more work to be done.

Acknowledgements This article was completed with the support of a William T. Grant Foundation Scholar Award (to Hammack) and Grant R01 HD078526 (to Meyer, Frost, and Hammack) from the Eunice Kennedy Shriver National Institute of Child Health and Human Development (NICHD). We acknowledge the research assistance of James E. Lykens, Lesley-Reid Harrison, Zeneva Schindler, Charlie Springer, and Andrew Vittoria, and we thank Andrew Pilecki and Brandon Balzer Carr for consultation. Portions of this article were presented at the annual Gay Men's Health Summit in Vancouver, British Columbia, in 2013. We thank Rick Marchand, Terry Trussler, and Olivier Ferlatte for the invitation and valuable feedback at the Summit.

\section{Compliance with Ethical Standards}

Conflicts of interest All authors declare that they have no conflicts of interest to disclose.

Human and animal rights This article does not contain any studies with human participants or animals performed by any of the authors.

\section{References}

Adams, J., McCreanor, T., \& Braun, V. (2013). Gay men's explanations of health and how to improve it. Qualitative Health Research, 23(7), 887-899.

Adelman, M., Gurevitch, J., de Vries, B., \& Blando, J. (2006). Openhouse: Community building and research in the LGBT aging population. In D. C. Kimmel, T. Rose, \& S. David (Eds.), Lesbian, gay, bisexual, and transgender aging: Research and clinical perspectives (pp. 247-264). New York: Columbia University Press.

Anderson, E. R. (1993). Analyzing change in short-term longitudinal research using cohort-sequential designs. Journal of Consulting and Clinical Psychology, 61(6), 929-940. 
Armstrong, E. A. (2002). Forging gay identities: Organizing sexuality in San Francisco, 1950-1994. Chicago: University of Chicago Press.

Arnett, J. J. (2004). Emerging adulthood: The winding road from the late teens through the twenties. New York: Oxford University Press.

Badget, M. V.L. (2011). Social inclusion and the value of marriage equality in Massachusetts and the Netherlands. Journal of Social Issues, 67(2), 316-334.

Baldwin, A., Dodge, B., Schick, V., Hubach, R. D., Bowling, J., et al. (2015). Sexual self-identification among behaviorally bisexual men in the midwestern United States. Archives of Sexual Behavior, 44(7), 2015-2026.

Batchelor, W. F. (1984). AIDS: A public health and psychological emergency. American Psychologist, 39(11), 1279-1284.

Batchelor, W. F. (1988). AIDS 1988: The science and the limits of science. American Psychologist, 43(11), 853-858.

Bauermeister, J. A. (2014). How statewide LGB policies go from "under our skin" to "into our hearts": Fatherhood aspirations and psychological wellbeing among emerging adult sexual minority men. Journal of Youth and Adolescence, 43(8), 1295-1305.

Bayer, R. (1987). Homosexuality and American psychiatry: The politics of diagnosis (2nd ed.). Princeton, NJ: Princeton University Press.

Berger, B. M. (1960). How long is a generation? British Journal of Sociology, $11(1), 10-23$.

Berger, R. M., \& Kelly, J. J. (2001). What are older gay men like? An impossible question? Journal of Gay \& Lesbian Social Services, 13(4), 55-65.

Bernstein, M. (2002). Identities and politics: Toward a historical understanding of the lesbian and gay movement. Social Science History, 26(3), 531-581.

Bowleg, L. (2013). “Once you've blended the cake, you can't take the parts back to the main ingredients": Black gay men's descriptions and experiences of intersectionality. Sex Roles, 68, 754-767.

Boxer, A. M. (1997). Gay, lesbian, and bisexual aging into the twenty-first century: An overview and introduction. Journal of Gay, Lesbian, \& Bisexual Identity, 2, 187-197.

Boxer, A. M., \& Cohler, B. J. (1989). The life course of gay and lesbian youth: An immodest proposal for the study of lives. Journal of Homosexuality, $17,315-355$.

Boykin, K. (2004). Beyond the down low: Sex, lies, and denial in Black America. New York: Carroll \& Graf.

Butler, S. S. (2004). Gay, lesbian, bisexual, and transgender (GLBT) elders: The challenges and resilience of this marginalized group. Journal of Human Behavior in the Social Environment, 9(4), 25-44.

Calzo, J. P., Antonucci, T. C., Mays, V. M., \& Cochran, S. D. (2011). Retrospective recall of sexual orientation identity development among gay, lesbian, and bisexual adults. Developmental Psychology, 47(6), 16581673.

Carter, D. (2004). Stonewall: The riots that sparked the gay revolution. New York: St. Martin's Press.

Cass, V. C. (1979). Homosexual identity formation: A theoretical model. Journal of Homosexuality, 4, 219-235.

Centers for Disease Control and Prevention. (2005). AIDS Public Information Data Set (APIDS) US surveillance data for 1981-1999. Retrieved February 3, 2017 from http://wonder.cdc.gov/aids-v1999.html.

Centers for Disease Control and Prevention. (2016). HIV among gay and bisexualmen. Retrieved August 25, 2016 from http://www.cdc.gov/hiv/ group/msm/.

Chan, C. S. (1989). Issues of identity development among Asian-American lesbians and gay men. Journal of Counseling \& Development, 68(1), 16-20.

Christian, T. Y. (2005). "Good cake": An ethnographic trilogy of life satisfaction among gay Black men. Men and Masculinities, 8(2), 164-174.

Clerkin, E. M., Newcomb, M. E., \& Mustanski, B. (2011). Unpacking the racial disparity in HIV rates: The effect of race on risky sexual behavior among Black young men who have sex with men (YMSM). Journal of Behavioral Medicine, 34(4), 237-243.
Clover, D. (2006). Overcoming barriers for older gay men in the use of health services: A qualitative study of growing older, sexuality, and health. Health Education Journal, 65(1), 41-52.

Cohler, B. J. (2007). Writing desire: Sixty years of gay autobiography. Madison, WI: University of Wisconsin Press.

Cohler, B. J., \& Galatzer-Levy, R. M. (2000). The course of gay and lesbian lives: Social and psychoanalytic perspectives. Chicago: University of Chicago Press.

Cohler, B. J., \& Hostetler, A. J. (2007). Gay lives in the third age: Possibilities and paradoxes. In P. Wink \& J. James (Eds.), The crown of life: Dynamics of the early post-retirement period (pp. 263-282). New York: Springer.

Cohort. (2016). In Oxford English Dictionary Online. Retrieved from www. oed.com.

Conerly, G. (2001). Are you Black first or are you queer? In D. ConstantineSimms (Ed.), The greatest taboo: Homosexuality in Black communities (pp. 7-23). Los Angeles: Alyson Publications.

Costa, P. T., \& McCrae, R. R. (1982). An approach to the attribution of aging, period, and cohort effects. Psychological Bulletin, 92(1), 238-250.

Crossley, M. L. (2008). Critical health psychology: Developing and refining the approach. Social and Personality Psychology Compass, 2(1), $21-33$.

Cruz, J. M. (2003). Sociological analysis of aging: The gay male perspective. New York: Harrington Park Press.

D’ Augelli, A. R., Rendina, J. H., Sinclair, K. O., \& Grossman, A. H. (2006), Lesbian and gay youth's aspirations for marriage and raising children. Journal of LGBTQ Issues in Counseling, 1(4), 77-98.

D’Emilio, J. (1983). Sexual politics, sexual communities: The making of a homosexual minority in the United States, 1940-1970. Chicago: University of Chicago Press.

Dannefer, D. (1984). Adult development and social theory: A paradigmatic reappraisal. American Sociological Review, 49, 100-116.

Davidson, A. G. (1991). Looking for love in the age of AIDS: The language of gay personals, 1978-1988. Journal of Sex Research, 28(1), 125-137.

Davis, K. C., Schraufnagel, T. J., Kajumulo, K. F., Gilmore, A. K., Norris, J., \& George, W. H. (2014). A qualitative examination of men's condom use attitudes and resistance: "It's just part of the game". Archives of Sexual Behavior, 43(3), 631-643.

de Vries, B. (2013). LG(BT) persons in the second half of life: The intersectional influences of stigma and cohort. LGBT Health, 1(1), 16-21.

de Vries, B., \& Herdt, G. (2012). Aging in the gay community. In T. M. Witten \& A. E. Eyler (Eds.), Gay, lesbian, bisexual, and transgender aging: Challenges in research, practice, and policy (pp. 84-129). Baltimore, MD: Johns Hopkins University Press.

Dickson, N., van Roode, T., Cameron, C., \& Paul, C. (2013). Stability and change in same-sex attraction, experience, and identity by sex and age in a New Zealand birth cohort. Archives of Sexual Behavior, 42, 753-763.

Dodge, B., Jeffries, W. L., \& Sandfort, T. G. M. (2008). Beyond the down low: Sexual risk, protection, and disclosure among at-risk Black men who have sex with both men and women (MSMW). Archives of Sexual Behavior, 37(5), 683-696.

Dodge, B., Schnarrs, P. W., Reece, M., Goncalves, G., Martinez, O., et al. (2012). Community involvement among behaviourally bisexual men in the midwestern USA: Experiences and perceptions across communities. Culture, Health \& Sexuality, 14(9), 1095-1110.

Dowsett, G. W. (2007). Researching gay men's health: The promise of qualitative methodology. In I. H. Meyer \& M. E. Northridge (Eds.), The health of sexual minorities: Public health perspectives on lesbian, gay, bisexual, and transgenderpopulations (pp.419-441). New York: Springer.

Duberman, M. (1991). Cures: A gay man's odyssey. New York: Dutton.

Duberman, M. (1993). Stonewall. New York: Dutton.

Dunlap, A. (2014). Coming-out narratives across generations. Journal of Gay \& Lesbian Social Services, 26(3), 318-335. 
Elder, G. H. (1974). Children of the Great Depression: Social change in life experience. Chicago: University of Chicago Press.

Elder, G. H. (1998). The life course as developmental theory. Child Development, 69, 1-12.

Elder, G. H., Johnson, M. K., \& Crosnoe, R. (2003). The emergence and development of life course theory. In J. T. Mortimer \& M. J. Shanahan (Eds.), Handbook of the life course (pp. 3-22). Hingham, MA: Kluwer.

Faderman, L. (2015). The gay revolution: The story of the struggle. New York: Simon \& Schuster.

Fenkl, E. A. (2012). Aging gay men: A review of the literature. Journal of LGBT Issues in Counseling, 6(3), 162-182.

Fingerhut, A. W., Riggle, E. D. B., \& Rostosky, S. S. (2011). Same-sex marriage: The social and psychological implications of policy and debates. Journal of Social Issues, 67(2), 225-241.

Flowers, P., \& Buston, K. (2001). "I was terrified of being different”: Exploring gay men's accounts of growing up in a heterosexist society. Journal of Adolescence, 24, 51-65.

Forstein, M. (2013). AIDS: A history. Journal of Gay \& Lesbian Mental Health, 17(1), 40-63.

Foucault, M. (1978). The history of sexuality: An introduction (Vol. 1). New York: Vintage.

Foucault, M. (1982). The subject and power. Critical Inquiry, 8, 777-795.

Fredriksen-Goldsen, K., \& Muraco, A. (2010). Aging and sexual orientation: A 25 year review of the literature. Research on Aging, 32(3), 372-413.

Friedman, M. R., Dodge, B., Schick, V., Herbenick, D., Hubach, R. D., et al. (2014). From bias to bisexual health disparities: Attitudes toward bisexual men and women in the United States. LGBT Health, 1(4), 309-318.

Frost, D. M., \& Meyer, I. H. (2012). Measuring community connectedness among diverse sexual minority populations. Journal of Sex Research, 49(1), 36-49.

Frost, D. M., Meyer,I. H., \& Hammack, P.L.(2015). Health and well-being in emerging adults' same-sex relationships: Critical questions and directions for research in developmental science. Emerging Adulthood, 3(1), 3-13.

Frost, D. M., \& Ouellette, S. C. (2011). A search for meaning: Recognizing the potential of narrative research in social policy-making efforts. Sexuality Research and Social Policy, 8(3), 151-161.

Geertz, C. (1973). The interpretation of cultures. New York: Basic Books.

Generation. (2016). In Oxford English Dictionary Online. Retrieved from www.oed.com.

Glenn, N. D. (1976). Cohort analysts' futile quest: Statistical attempts to separate age, period and cohort effects. American Sociological Review, 41(5), 900-904.

Gonzalez, M. A. (2007). Latinos on da down low: The limitations of sexual identity in public health. Latino Studies, 5(1), 25-52.

Goode-Cross, D. T., \& Tager, D. (2011). Negotiating multiple identities: How African-American gay and bisexual men persist at a predominantly white institution. Journal of Homosexuality, 58(9), 1235-1254.

Grant, R. M., Lama, J. R., Anderson, P. L., McMahan, V., Liu, A. Y., et al. (2010). Preexposure chemoprophylaxis for HIV prevention in men who have sex with men. New England Journal of Medicine, 363(27), 25872599.

Grierson, J., \& Smith, A. M. A. (2005). In from the outer: Generational differences in coming out and gay identity formation. Journal of Homosexuality, 50(1), 53-70.

Grov, C., Bamonte, A., Fuentes, A., Parsons, J. T., Bimbi, D. S., \& Morgenstern, J. (2008). Exploring the internet's role in sexual compulsivity and out of control sexual thoughts/behaviour: A qualitative study of gay and bisexual men in New York City. Culture, Health \& Sexuality, 10(2), $107-124$

Grov, C., Breslow, A. S., Newcomb, M. E., Rosenberger, J. G., \& Bauermeister, J. A. (2014). Gay and bisexual men's use of the Internet: Research from the 1990s through 2013. Journal of Sex Research, 51(4), 390-409.

Grov, C., Rendina, H. J., Ventuneac, A., \& Parsons, J. T. (2016). Sexual behavior varies between same-race and different-race partnerships: A daily diary study of highly sexually active Black, Latino, and white gay and bisexual men. Archives of Sexual Behavior, 45, 1453-1462.

Haile, R., Padilla, M. B., \& Parker, E. A. (2011). "Stuck in the quagmire of an HIV ghetto": The meaning of stigma in the lives of older Black gay and bisexual men living with HIV in New York City. Culture, Health \& Sexuality, 13(4), 429-442.

Haile, R., Rowell-Cunsolo, T. L., Parker, E. A., Padilla, M. B., \& Hansen, N. B. (2014). An empirical test of racial/ethnic differences in perceived racism and affiliation with the gay community: Implications for HIV risk. Journal of Social Issues, 70(2), 342-359.

Halkitis, P. N. (2014). The AIDS generation: Stories of survival and resilience. New York: Oxford University Press.

Halkitis, P. N., Kapadia, F., Bub, K. L., Barton, S., Moreira, A. D., et al. (2015). A longitudinal investigation of syndemic conditions among young gay, bisexual, and other MSM: The P18 Cohort Study. AIDS and Behavior, 19(6), 970-980.

Halkitis, P. N., Siconolfi, D. E., Stults, C. B., Barton, S., Bub, K., et al. (2014). Modeling substance use in emerging adult gay, bisexual, and other YMSM across time: The P18 cohort study. Drug and Alcohol Dependence, 145, 209-216.

Hammack, P. L. (2005). The life course development of human sexual orientation: An integrative paradigm. Human Development, 48, 267-290.

Hammack, P. L. (2011). Narrative and the politics of meaning. Narrative Inquiry, 21(2), 311-318.

Hammack, P. L., \& Cohler, B. J. (2009). Narrative engagement and sexual identity: An interdisciplinary approach to the study of sexual lives. In P. L. Hammack \& B. J. Cohler (Eds.), The story of sexual identity: Narrative perspectives on the gay and lesbian life course (pp. 3-22). New York: Oxford University Press.

Hammack, P. L., \& Cohler, B. J.(2011). Narrative, identity, and the politics of exclusion: Social change and the gay and lesbian life course. Sexuality Research and Social Policy, 8, 162-182.

Hammack, P. L., Mayers, L., \& Windell, E. P. (2013). Narrative, psychology, and the politics of sexual identity in the United States: From "sickness" to "species" to "subject". Psychology \& Sexuality, 4(3), 219-243.

Harper, G. W., Bruce, D., Serrano, P., \& Jamil, O. B. (2009). The role of the Internet in the sexual identity development of gay and bisexual male adolescents. In P. L. Hammack \& B. J. Cohler(Eds.), The story of sexual identity: Narrative perspectives on the gay and lesbian life course (pp. 297-326). New York: Oxford University Press.

Herdt, G., \& Boxer, A. (1993). Children of Horizons: How gay and lesbian teens are leading a new way out of the closet. Boston: Beacon.

Herdt, G., \& McClintock, M. (2000). The magical age of 10. Archives of Sexual Behavior, 29(6), 587-606.

Herek, G. M. (2010). Sexual orientation differences as deficits: Science and stigma in the history of American psychology. Perspectives on Psychological Science, 5(6), 693-699.

Herek, G. M., \& Glunt, E. K. (1988). An epidemic of stigma: Public reactions to AIDS. American Psychologist, 43(11), 886-891.

Hidalgo, M. A., Cotten, C., Johnson, A. K., Kuhns, L. M., \& Garofalo, R. (2013). "Yes, I am more than just that": Gay/bisexual young men residing in the US discuss the influence of minority stress on their sexual risk behavior prior to HIV infection. International Journal of Sexual Health, 25(4), 291-304.

Hirshman, L. (2012). Victory: The triumphant gay revolution. New York: Harper Perennial.

Hunter, M. A. (2010). All the gays are White and all the Blacks are straight: Black gay men, identity, and community. Sexuality Research \& Social Policy, 7(2), 81-92.

Icard,L. (1985). Black gay men and conflicting social identities: Sexual orientation versus racial identity. Journal of Social Work \& Human Sexuality, 4(1-2), 83-93.

Institute of Medicine. (2011). The health of lesbian, gay, bisexual, and transgender people: Building a foundation for better understanding. Washington, DC: National Academies Press. 
Jackson, N. C., Johnson, M. J., \& Roberts, R. (2008). The potential impact of discrimination fears of older gays, lesbians, bisexual and transgender individuals living in small- to moderate-sized cities on long term health care. Journal of Homosexuality, 54(3), 325-339.

Johnson, M. L. (1982). Influence of assimilation on the psychological adjustment of Black homosexual men. Ann Arbor, MI: University of Michigan.

Joseph, J. G., Caumartin, S. M., Tal, M., Kirscht, J. P., Kessler, R. C., et al. (1990). Psychological functioning in a cohort of gay men at risk for AIDS: A three-year descriptive study. Journal of Nervous and Mental Disease, 178(10), 607-615.

Juran, S. (1989). Sexual behavior changes as a result of concern about AIDS: Gays, straights, females and males. Journal of Psychology \& Human Sexuality, 2(2), 61-77.

Katoff, L., \& Dunne, R. (1988). Supporting people with AIDS: The Gay Men's Health Crisis model. Journal of Palliative Care, 4(4), 88-95.

Katz-Wise, S. L., \& Hyde, J. S. (2015). Sexual fluidity and related attitudes and beliefs among young adults with a same-gender orientation. Archives of Sexual Behavior, 44(5), 1459-1470.

Kayal,P.M.(1993). Bearing witness: Gaymen's health crisis and the politics of AIDS. Boulder, CO: Westview.

Keleher, A., \& Smith, E. R. (2012). Growing support for gay and lesbian equality since 1990. Journal of Homosexuality, 59, 1307-1326.

Kertzer, D. I. (1983). Generation as a sociological problem. Annual Review of Sociology, 9, 125-149.

Kertzner, R. M. (1997). Entering midlife: Gay men, HIV and the future. Journal of the Gay \& Lesbian Medical Association, 1, 87-95.

Kertzner, R. M. (2001). The adult life course and homosexual identity in midlife gay men. Annual Review of Sex Research, 12, 75-92.

Kertzner, R. M., Meyer, I. H., Frost, D. M., \& Stirratt, M. J. (2009). Social and psychological well-being in lesbians, gay men, and bisexuals: The effects of race, gender, age, and sexual identity. American Journal of Orthopsychiatry, 79(4), 500-510.

LeVay, S. (1996). Queer science: The use and abuse of research into homosexuality. Cambridge, MA: MIT Press.

Levine, M. P. (1979). Gay ghetto. Journal of Homosexuality, 4(4), 363-377.

Loiacano, D. K. (1989). Gay identity issues among Black Americans: Racism, homophobia, and the need for validation. Journal of Counseling \& Development, 68(1), 21-25.

Loughery,J.(1998). The other side of silence: Men'slives and gayidentities, a twentieth-century history. New York: Henry Holt.

Maisel, N. C., \& Fingerhut, A. W. (2011). California's ban on same-sex marriage: The campaign and its effects on gay, lesbian, and bisexual individuals. Journal of Social Issues, 67(2), 242-263.

Mannheim, K. (1959). The problem of generations. In P. Kesckemeti (Ed.), Essays on the sociology of knowledge (pp. 276-322). London: Routledge and Kegan Paul (Original work published 1923).

Martin, J. L. (1986). AIDS risk reduction recommendations and sexual behavior patterns among gay men: A multifactorial categorical approach to assessing change. Health Education Quarterly, 13, 347-358.

Martin, J. L. (1987). The impact of AIDS on gay male sexual behavior patterns in New York City. American Journal of Public Health, 77, $578-581$.

Martin, J. L. (1988). Psychological consequences of AIDS-related bereavement among gay men. Journal of Consulting and Clinical Psychology, $56(6), 856-862$

Martin, J. I., \& D'Augelli, A. R. (2009). Timed lives: Cohort and period effects in research on sexual orientation and gender identity. In W. Meezan \& J. I. Martin (Eds.), Handbook of research with gay, lesbian, bisexual, and transgender populations (pp. 190-207). New York: Routledge.

Martin, J. L., \& Dean, L. (1993). Effects of AIDS-related bereavement and HIV-related illness on psychological distress among gay men: A 7-year longitudinal study, 1985-1991. Journal of Consulting and Clinical Psychology, 61(1), 94-103.
Martin, J.L., Dean, L., Garcia, M., \& Hall, W. (1989). The impact of AIDS on a gay community: Changes in sexual behavior, substance use, and mental health. American Journal of Community Psychology, 17(3), 269-293.

Martinez, J., \& Hosek, S. G. (2005). An exploration of the down-low identity: Nongay-identified young African-American men who have sex with men. Journal of the National Medical Association, 97(8), 1103-1112.

Martinez, D. G., \& Sullivan, S. C. (1998). African American gay men and lesbians: Examining the complexity of gay identity development. Journal of Human Behavior in the Social Environment, 1, 243-264.

Marzullo, M. A., \& Herdt, G. (2011). Marriage rights and LGBTQyouth: The present and future impact of sexuality policy changes. Ethos, 39(4), 526-552.

Mays, V.M., Cochran, S. D., \&Zamudio, A. (2004). HIV prevention research: Are we meeting the needs of African American men who have sex with men? Journal of Black Psychology, 30(1), 78-105.

McCormack, M., Anderson, E., \& Adams, A. (2014). Cohort effect on the coming out of bisexual men. Sociology, 48(6), 1207-1223.

McKusick, L., Horstman, W., \& Coates, T. J.(1985). AIDS and sexual behavior reported by gay men in San Francisco. American Journal of Public Health, 75, 493-496.

Meyer, I. H. (2003). Prejudice, social stress, and mental health in lesbian, gay, and bisexual populations: Conceptual issues and research evidence. Psychological Bulletin, 129(5), 674-697.

Meyer, I. H. (2010). Identity, stress, and resilience in lesbians, gay men, and bisexuals of color. The Counseling Psychologist, 38(3), 442-454.

Meyer, I., \& Ouellette, S. (2009). Unity and purpose at the intersections of racial/ethnic and sexual identities. In P. L. Hammack \& B. J. Cohler (Eds.), The story of sexual identity: Narrative perspectives on the gay and lesbian life course (pp. 79-106). New York: Oxford University Press.

Miller, M. (2001). "Ethically questionable?" Popular media reports on bisexual men and AIDS. Journal of Bisexuality, 2(1), 95-112.

Minton, H. L. (2001). Departing from deviance: A history of homosexual rights and emancipatory science in America. Chicago: University of Chicago Press.

Morgan, E. M. (2013). Contemporary issues in sexual orientation and identity development in emerging adulthood. Emerging Adulthood, 1(1), 5266.

Morin, S. F., Charles, K. A., \& Malyon, A. K. (1984). The psychological impact of AIDS on gay men. American Psychologist, 39(11), 12881293.

Muraco, A., LeBlanc, A. J., \& Russell, S. T. (2008). Conceptualizations of family by older gay men. Journal of Gay \& Lesbian Social Services, 20(1-2), 69-90.

Mustanski, B., Lyons, T., \& Garcia, S. C. (2011). Internet use and sexual health of young men who have sex with men: A mixed-methods study. Archives of Sexual Behavior, 40(2), 289-300.

Mutchler, M. G., McDavitt, B., Ghani, M. A., Nogg, K., Winder, T. J. A., et al. (2015). Getting prepared for HIV prevention navigation: Young Black gay men talk about HIV prevention in the biomedical era. AIDS Patient Care and STDs, 29(9), 490-502.

Newcomb, M. E., \& Mustanski, B. (2013). Racial differences in same-race partnering and the effects of sexual partnership characteristics on HIV risk in MSM: A prospective sexual diary study. Journal of Acquired Immune Deficiency Syndromes, 62, 329-333.

Newcomb, M. E., \& Mustanski, B. (2014). Developmental change in the relationship between alcohol and drug use before sex and sexual risk behavior in young men who have sex with men. AIDS and Behavior, 18(10), 1981-1990.

Odets, W. (1995). In the shadow of the epidemic: Being HIV-negative in the age of AIDS. Durham, NC: Duke University Press.

Pachankis, J. E., Hatzenbuehler, M. L., \& Starks, T. L. (2014). The influence of structural stigma and rejection sensitivity on young sexual minority men's daily tobacco and alcohol use. Social Science and Medicine, 103, $67-75$. 
Parks, C. A. (1999). Lesbian identity development: An examination of differences across generations. American Journal of Orthopsychiatry, 69, 347-361.

Patton, L. D. (2011). Perspectives on identity, disclosure, and the campus environment among African American gay and bisexual men at one historically Black college. Journal of College Student Development, 52(1), 77-100.

Peacock, J. R. (2000). Gay male development: Some stage issues of an older cohort. Journal of Homosexuality, 40(2), 13-29.

Phelps, E., Furstenberg, F. F., \& Colby, A. (Eds.). (2002). Looking at lives: American longitudinal studies of the twentieth century. New York: Russell Sage Foundation.

Plummer, K. (2010). Generational sexualities, subterranean traditions, and the hauntings of the sexual world: Some preliminary remarks. Symbolic Interaction, 33(2), 163-190.

Ramirez-Valles, J., Kuhns, L. M., Campbell, R. T., \& Diaz, R. M. (2010). Social integration and health community involvement, stigmatized identities, and sexual risk in Latino sexual minorities. Journal of Health and Social Behavior, 51(1), 30-47.

Reed, S. J., \& Miller, R. L. (2016). Thriving and adapting: Resilience, sense of community, and syndemics among young Black gay and bisexual men. American Journal of Community Psychology, 57, 129-143.

Remafedi, G. (1994). Cognitive and behavioral adaptations to HIV/AIDS among gay and bisexual adolescents. Journal of Adolescent Health, 15(2), 142-148.

Richards, T. A., Wrubel, J., \& Folkman, S. (1999). Death rites in the San Francisco gay community: Cultural developments of the AIDS epidemic. Omega: Journal of Death and Dying, 40(2), 335-350.

Robinson, P. (2008). The changing world of gay men. New York: Palgrave Macmillan.

Rofes, E. E. (2005). Gay bodies, gay selves: Understanding the gay men's health movement. White Crane, 66, 15-17.

Rosow, I. (1978). What is a cohort and why? Human Development, 21, 65-75.

Rostosky, S. S., Riggle, E. D. B., Horne, S. G., \& Miller, A. D. (2009). Marriage amendments and psychological distress in lesbian, gay, and bisexual (LGB) adults. Journal of Counseling Psychology, 56(1), 56-66.

Rotheram-Borus, M. J., Hunter, J., \& Rosario, M. (1994). Suicidal behavior and gay-related stress among gay and bisexual male adolescents. Journal of Adolescent Research, 9, 498-508.

Ryder, N. B. (1965). The cohort as a concept in the study of social change. American Sociological Review, 30(6), 843-861.

Sadownick, D. (1996). Sex between men: An intimate history of the sex lives of gay men postwar to present. San Francisco: Harper San Francisco.

Savin-Williams, R. C. (2001). A critique of research on sexual-minority youths. Journal of Adolescence, 24, 5-13.

Savin-Williams, R. C. (2005). The new gay teenager. Cambridge, MA: Harvard University Press.
Savin-Williams, R. C., Joyner, K., \& Rieger, G. (2012). Prevalence and stability of self-reported sexual orientation identity during young adulthood. Archives of Sexual Behavior, 41(1), 103-110.

Schaie, K. W. (1965). A general model for the study of developmental problems. Psychological Bulletin, 64(2), 92-107.

Schope, R. D. (2002). The decision to tell: Factors influencing the disclosure of sexual orientation by gay men. Journal of Gay \& Lesbian Social Services, 14(1), 1-22.

Shaw, R. (2010). Embedding reflexivity within experiential qualitative psychology. Qualitative Research in Psychology, 7(3), 233-243.

Shweder, R. A., \& Sullivan, M. A. (1993). Cultural psychology: Who needs it? Annual Review of Psychology, 44, 497-523.

Stein, M. (2012). Rethinking the gay and lesbian movement. New York: Routledge.

Troiden, R. R. (1979). Becoming homosexual: A model of gay identity acquisition. Psychiatry, 42, 362-373.

Vaccaro, A. (2009). Intergenerational perceptions, similarities and differences: A comparative analysis of lesbian, gay, and bisexual millennial youth with Generation X and Baby Boomers. Journal of LGBT Youth, 6(2-3), 113-134.

Voisin, D. R., Bird, J. D. P., Shiu, C., \& Krieger, C. (2013). “It's crazy being a Black, gay youth." Getting information about HIV prevention: A pilot study. Journal of Adolescence, 36(1), 111-119.

Wachter, R. M. (1992). AIDS, activism, and the politics of health. New England Journal of Medicine, 326(2), 128-133.

Weinrich, J. D. (1997). Strange bedfellows: Homosexuality, gay liberation, and the Internet. Journal of Sex Education \& Therapy, 22(1), 58-66.

Wilson, P. A., Meyer, I. H., Antebi-Gruszka, N., Boone, M. R., Cook, S. H., et al. (2016). Profiles of resilience and psychosocial outcomes among young Black gay and bisexual men. American Journal of Community Psychology, 57, 144-157.

Wilson, B. D. M., \& Miller, R. L. (2002). Strategies for managing heterosexism used among African American gay and bisexual men. Journal of Black Psychology, 28(4), 371-391.

Winkelstein, W., Samuel, M., Padian, N., Wiley, J. A., Lang, W., Anderson, R. E., \& Levy, J. A. (1987). The San Francisco Men's Health Study: III. Reduction in human immunodeficiency virus transmission among homosexual/bisexual men, 1982-1986. American Journal of Public Health, 75, 493-496.

Woody, I. (2014). Aging out: A qualitative exploration of ageism and heterosexism among aging African American lesbians and gay men. Journal of Homosexuality, 61(1), 145-165.

World Health Organization. (1948). WHO definition of health. Retrieved March 4, 2016 from http://www.who.int/about/definition/en/print.html. 